\title{
Comparison of sandblasted and acid-etched surface implants and new hydrophilic surface implants in the posterior maxilla using a 3-month early-loading protocol: a randomized controlled trial
}

\author{
Hyeong Gi Kim ${ }^{1,2}$, Pil-Young Yun ${ }^{1}$, Young-Kyun Kim ${ }^{1,3,4}$, II-hyung Kim ${ }^{1,4}$ \\ ${ }^{1}$ Department of Oral and Maxillofacial Surgery, Section of Dentistry, Seoul National University Bundang Hospital, Seongnam, \\ ${ }^{2}$ Office of Human Resources Development, Armed Forces Capital Hospital, Armed Forces Medical Command, Seongnam, \\ ${ }^{3}$ School of Dentistry and Dental Research Institute, Seoul National University, Seoul, \\ ${ }^{4}$ Department of Oral and Maxillofacial Surgery, Armed Forces Capital Dental Hospital, Armed Forces Medical Command, Seongnam, Korea
}

\begin{abstract}
J Korean Assoc Oral Maxillofac Surg 2021;47:175-182)
Objectives: In this prospective randomized controlled trial, we measured the primary and secondary stability of two surface-treated implants placed in the posterior maxilla, applied 3-month loading protocols, and compared and analyzed the short-term outcomes of the implants.

Patients and Methods: From June 2018 to June 2019, patients with a residual bone height of $4 \mathrm{~mm}$ in the posterior maxilla were enrolled and randomly divided into two groups to place SA implants (Osstem Implants, Korea) in Group A and NH implants (Hiossen, USA) in Group B. Finally, 14 implants placed in 13 patients in Group A and 17 implants placed in 14 patients in Group B were analyzed. The measured primary and secondary stability of each implant was represented by implant stability quotient (ISQ), and treatment outcomes were evaluated.

Results: Group A consisted of patients with an average age of 62.2 years (range, 48-80 years), and Group B consisted of patients with an average age of 58.1 years (range, $35-82$ years). Primary stability was $73.86 \pm 6.40$ and $71.24 \pm 5.32$ in Groups A and B, respectively $(P=0.222)$. Secondary stability was 79.07 \pm 5.21 in Group A and 78.29 \pm 4.74 in Group B $(P=0.667)$. A steep increase in ISQ during the healing period was observed in Group B, though it was not significant $(P=0.265)$. The mean follow-up period was $378.5 \pm 164.6$ days in Group A and 385.3 \pm 167.9 days in Group B. All implants in each group met the success criteria, and the success rate was $100 \%$.

Conclusion: Two surface-treated implants placed in the posterior maxilla with greater than $4 \mathrm{~mm}$ alveolar bone height exhibited successful one-year treatment outcomes if a primary stability of 65 or higher ISQ was obtained and a 3-month early loading protocol was applied.
\end{abstract}

Key words: Dental implants, Dental implantation, Artificial teeth, Randomized controlled trial

[paper submitted 2020. 12. 30 / revised 2021. 1. 21 / accepted 2021. 2. 1]

\section{Introduction}

Osseointegration refers to direct structural and functional linkage between bone and implant surface without the presence of soft tissue ${ }^{1}$. The conventional protocol loads the implant after a 4- to 6-month healing period to provide suf-

\footnotetext{
Il-hyung Kim

Department of Oral and Maxillofacial Surgery, Armed Forces Capital Dental Hospital, 81 Saemaeul-ro 177beon-gil, Bundang-gu, Seongnam 13574, Korea

TEL: +82-31-725-6415

E-mail:haonflower@gmail.com

ORCID: https://orcid.org/0000-0003-1386-6391

(a) This is an open-access article distributed under the terms of the Creative Commons Attribution Non-Commercial License (http://creativecommons.org/ licenses/by-nc/4.0/), which permits unrestricted non-commercial use, distribution and reproduction in any medium, provided the original work is properly cited. Copyright (O) 2021 The Korean Association of Oral and Maxillofacial Surgeons. All rights reserved.
}

ficient osseointegration after implant placement and before functioning. However, in recent years, excellent clinical results using early-loading and immediate-loading protocols have been published ${ }^{2-4}$. Together with these studies, patient demand for shorter implant treatment periods is driving the development of implant surface treatment methods that enable faster osseointegration.

Various implant surface treatments have been developed to promote osseointegration between implant surface and alveolar bone and to improve biocompatibility. Among these approaches, the sandblasted and acid-etched (SLA) surface treatment method is the most widely used and allows rapid and firm osseointegration by improving surface roughness ${ }^{5}$. Studies on modified SLA surfaces have been conducted in the field of dental implantology, and there are ongoing efforts to obtain faster and improved osseointegration. This includes 
not only surface roughness, but also introduction of nanostructures and changes in physical properties such as crystallinity and hydrophilicity ${ }^{6}$.

This prospective comparative study observed the osseointegration and treatment progress of two randomly assigned groups of implants (SLA surface or dual surface with enhanced hydrophilicity) placed in the maxillary posterior region with a 3-month loading protocol. The purpose of this study was to compare and evaluate primary and secondary stability and short-term clinical outcomes of two surfacetreated implants and to share clinical experiences on the criteria for early loading in the maxillary posterior region.

\section{Patients and Methods}

This study was conducted under approval of the Institutional Review Board (IRB No. B-1802/451-004) of Seoul National University Bundang Hospital (Seongnam, Korea), and the written informed consent was obtained from all patients. From June 2018 to June 2019, 39 patients who visited Seoul National University Bundang Hospital were subjected to initial clinical and radiological examinations and then screened according to inclusion and exclusion criteria.

The inclusion criteria were as follows: 1) adult patients with complete jaw growth, 2) one or two consecutive teeth missing in the unilateral maxillary posterior region, 3) greater than $4 \mathrm{~mm}$ residual alveolar bone height of the partially edentulous region, 4) buccopalatally and mesiodistally sufficient available alveolar bone, 5) presence of opposing teeth (natu- ral, prosthetic, or implant-restored teeth), 6) implant stability quotient (ISQ) of 65 or higher immediately after implant placement.

The exclusion criteria were as follows: 1) uncontrolled systemic disease or pregnancy, 2) extensive bone graft due to severe atrophy of alveolar bone, 3) no opposing teeth or presence of dentures, 4) presence of severe oral parafunctional habits (bruxism, clenching, etc.), 5) implant treatment restriction due to noncooperation or poor oral hygiene, 6) ISQ value below 65 immediately after implant placement.

All participants were randomly assigned and classified into Group A or Group B. For Group A patients, TSIII SA implants (Osstem Implants, Busan, Korea) with an SLA surface were used. Group B received ETIII NH implants (Hiossen, Philadelphia, PA, USA), which exhibited hydrophilicity through partial application of a nano hydroxyapatite (HA) coating on the SLA surface. All implants in Groups A and B had the same surface morphology with a tapered shape and were internally connected. In Group A, 21 SA implants were placed in 19 patients, and in Group B, 25 NH implants were placed in 20 patients. Implant treatment was performed by an oral and maxillofacial surgeon and a prosthodontist at each stage. Cases in which the above criteria were not met during treatment and follow-up or for which study consent was withdrawn or follow-up loss occurred were excluded from the study.(Fig. 1)

The implants were placed based on the drilling sequence guidelines of the manufacturer. Appropriate implant diameter and length were selected based on width or height of

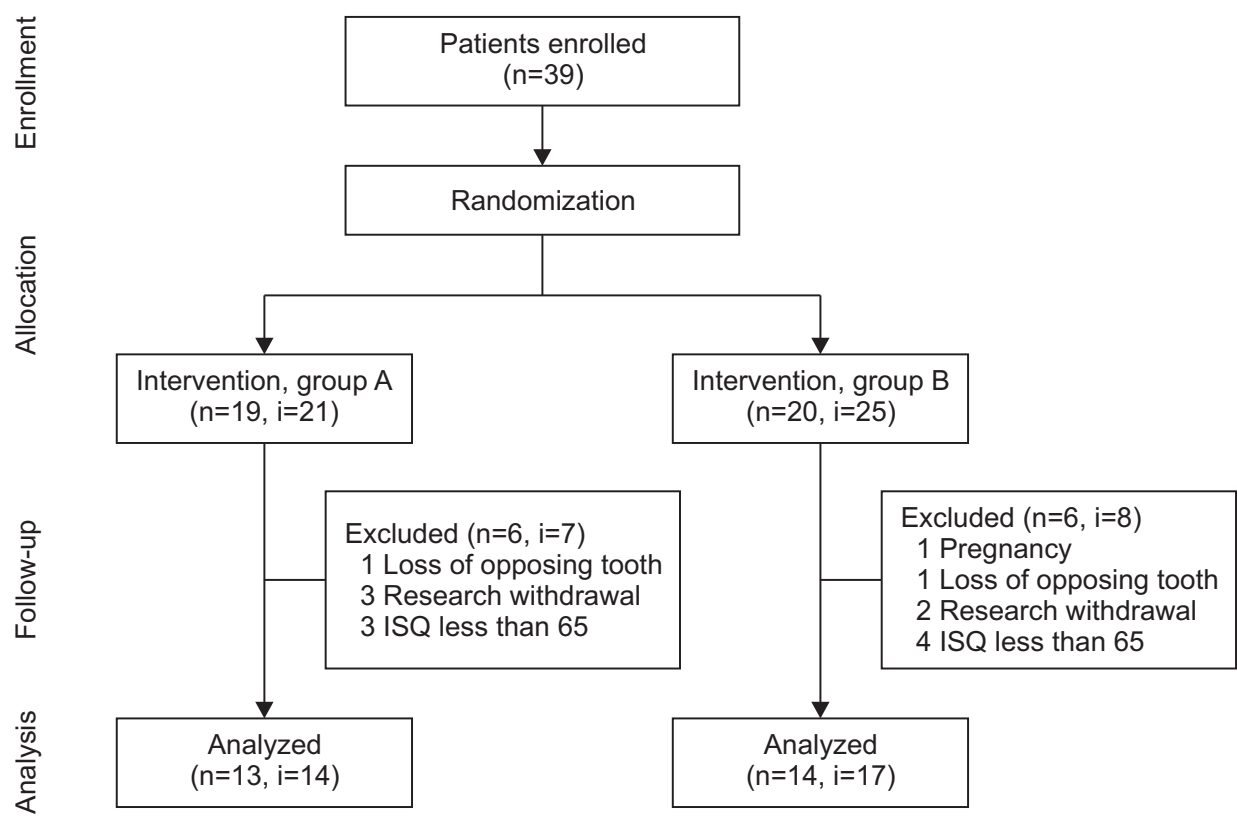

Fig. 1. Patient enrollment and exclusion. (i: implant, ISQ: implant stability quotient)

Hyeong Gi Kim et al: Comparison of sandblasted and acid-etched surface implants and new hydrophilic surface implants in the posterior maxilla using a 3-month early-loading protocol: a randomized controlled trial. J Korean Assoc Oral Maxillofac Surg 2021 
remaining alveolar bone. Crestal approaches of sinus lifting with bone graft (SLwBG), sinus lifting without bone graft (SLwoBG), and/or guided bone regeneration (GBR) in a small range were performed as auxiliary surgeries to accompany implant placement. At the time of surgery, submerged or non-submerged methods were selected based on operator decision. An Osstell Mentor (Osstell AB, Gothenburg, Sweden) was used to determine the mechanical stability of each implant using resonance frequency analysis (RFA) and quantifying the result as an ISQ value ${ }^{7}$. Primary stability was defined as the ISQ value immediately after implant placement, and secondary stability was defined as the ISQ value at the time of prosthetic impression acquisition or secondary surgery after the healing period. Stability was measured using the average of repeat measurements of buccal and palatal sides. Impressions were created 2.5 months after placement in all patients, and functioning began within 2 weeks after. All implants were restored with a single or splinted fixed implant prosthesis.

Marginal bone level was evaluated on digital periapical radiography (PACS; INFINIT, Seoul, Korea) using the parallel- ing cone technique. The ratio of actual implant fixture length and fixture length measured on the radiograph was calculated and corrected to consider the three-dimensional tilting of the fixture. The shortest vertical distance from implant shoulder to implant-bone contact point was set as the marginal bone level. Marginal bone loss (MBL) was defined as the interval change of the mean of mesial and distal marginal bone levels of the implant. Radiographs performed immediately after implant placement and at the most recent visit were evaluated. The post-treatment course of each implant was investigated.

The success of each implant was evaluated based on the criteria suggested by Zarb and Albrektsson ${ }^{8}$. Implants that were retained in the most recent follow-up were classified as survival, and the success rate and survival rate for each group were calculated. Quantitative variables were analyzed statistically using IBM SPSS Statistics (ver. 25.0; IBM, Armonk, NY, USA). A parametric or a non-parametric method was used to analyze the data depending on normality. If necessary, post-hoc analysis was conducted. The level of statistical significance was $95 \%$.

Table 1. Demographics and details of implant surgeries

\begin{tabular}{|c|c|c|c|c|c|c|c|c|}
\hline \multirow{2}{*}{ Group } & \multirow{2}{*}{ Patient No. } & \multirow{2}{*}{ Sex } & \multirow{2}{*}{ Age (yr) } & \multirow{2}{*}{ Location } & \multicolumn{2}{|c|}{ Implants } & \multirow{2}{*}{$\begin{array}{l}\text { Surgery } \\
\text { type }\end{array}$} & \multirow{2}{*}{$\begin{array}{l}\text { Auxiliary } \\
\text { surgery }\end{array}$} \\
\hline & & & & & Width & Length & & \\
\hline \multirow[t]{14}{*}{ A (SA implants) } & 1 & $\mathrm{M}$ & 65 & $\# 26$ & 5 & 8.5 & NS & SLwBG \\
\hline & & & & \#27 & 5 & 8.5 & NS & SLwBG \\
\hline & 2 & $\mathrm{~F}$ & 80 & $\# 26$ & 5 & 8.5 & NS & SLwBG \\
\hline & 3 & $\mathrm{~F}$ & 60 & $\# 26$ & 4.5 & 8.5 & NS & SLwBG \\
\hline & 4 & M & 64 & \#26 & 5 & 8.5 & NS & SLwBG \\
\hline & 5 & M & 63 & $\# 15$ & 4.5 & 10 & NS & \\
\hline & 6 & $\mathrm{~F}$ & 60 & \#16 & 5 & 8.5 & NS & SLwBG \\
\hline & 7 & M & 69 & $\# 25$ & 4.5 & 8.5 & NS & GBR \\
\hline & 8 & M & 65 & $\# 26$ & 5 & 10 & NS & GBR \\
\hline & 9 & M & 63 & $\# 17$ & 5 & 8.5 & NS & SLwBG \\
\hline & 10 & $\mathrm{M}$ & 61 & \#25 & 4.5 & 8.5 & NS & SLwBG \\
\hline & 11 & M & 59 & $\# 17$ & 5 & 10 & $\mathrm{~S}$ & GBR \\
\hline & 12 & M & 48 & \#16 & 5 & 8.5 & NS & SLwBG \\
\hline & 13 & M & 52 & \#27 & 5 & 8.5 & NS & GBR \\
\hline \multirow[t]{17}{*}{ B (NH implants) } & 1 & $\mathrm{~F}$ & 63 & $\# 17$ & 5 & 8.5 & NS & \\
\hline & 2 & $\mathrm{~F}$ & 55 & \#26 & 5 & 8.5 & NS & SLwBG, GBR \\
\hline & 3 & $\mathrm{M}$ & 55 & \#26 & 5 & 8.5 & $\mathrm{~S}$ & SLwBG, GBR \\
\hline & & & & \#27 & 5 & 8.5 & $\mathrm{~S}$ & SLwBG \\
\hline & 4 & $\mathrm{~F}$ & 82 & $\# 24$ & 4.5 & 10 & NS & - \\
\hline & 5 & M & 56 & \#16 & 5 & 8.5 & $\mathrm{~S}$ & SLwBG, GBR \\
\hline & 6 & $\mathrm{~F}$ & 35 & $\# 16$ & 5 & 8.5 & NS & SLwoBG \\
\hline & 7 & $\mathrm{~F}$ & 57 & $\# 16$ & 5 & 8.5 & NS & - \\
\hline & 8 & M & 56 & $\# 24$ & 4.5 & 10 & NS & - \\
\hline & 9 & M & 66 & $\# 26$ & 5 & 8.5 & NS & SLwBG \\
\hline & & & & $\# 27$ & 5 & 8.5 & NS & SLwBG \\
\hline & 10 & M & 58 & \#16 & 5 & 10 & NS & - \\
\hline & 11 & $\mathrm{~F}$ & 62 & $\# 26$ & 5 & 8.5 & NS & SLwoBG \\
\hline & 12 & M & 56 & $\# 16$ & 5 & 8.5 & NS & SLwBG \\
\hline & & & & $\# 17$ & 5 & 8.5 & NS & SLwBG \\
\hline & 13 & $\mathrm{~F}$ & 43 & $\# 16$ & 4.5 & 8.5 & $\mathrm{~S}$ & - \\
\hline & 14 & $\mathrm{~F}$ & 69 & $\# 14$ & 4.5 & 8.5 & $\mathrm{~S}$ & GBR \\
\hline
\end{tabular}

(M: male, F: female, NS: non-submerged, S: submerged, SLwBG: sinus lifting with bone graft, GBR: guided bone regeneration, SLwoBG: sinus lifting without bone graft)

Hyeong Gi Kim et al: Comparison of sandblasted and acid-etched surface implants and new hydrophilic surface implants in the posterior maxilla using a 3-month early-loading protocol: a randomized controlled trial. J Korean Assoc Oral Maxillofac Surg 2021 
Table 2. Primary and secondary implant stability

\begin{tabular}{clcccc}
\hline & & Group A $^{1}$ & Group B $^{2}$ & $t$ & $P$-value \\
\hline Stability (ISQ) & Primary & $73.86 \pm 6.40$ & $71.24 \pm 5.32$ & 1.247 & 0.222 \\
& Secondary & $79.07 \pm 5.21$ & $78.29 \pm 4.74$ & 0.435 & 0.667 \\
\hline
\end{tabular}

(ISQ: implant stability quotient, Group A: SA implants, Group A: NH implants)

${ }^{1,2}$ Statistically significant differences between primary and secondary stability in each group.

Hyeong Gi Kim et al: Comparison of sandblasted and acid-etched surface implants and new hydrophilic surface implants in the posterior maxilla using a 3-month early-loading protocol: a randomized controlled trial. J Korean Assoc Oral Maxillofac Surg 2021

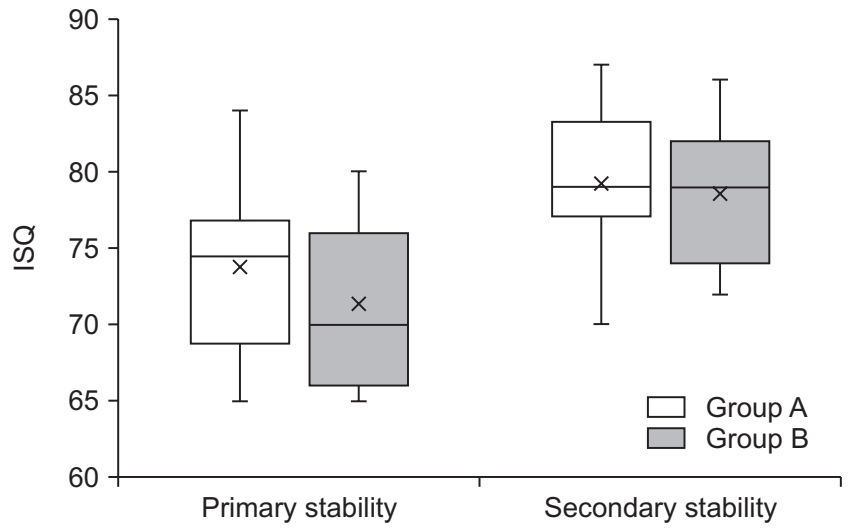

Fig. 2. Box plot of primary and secondary stability of the two groups of implants. (ISQ: implant stability quotient)

Hyeong Gi Kim et al: Comparison of sandblasted and acid-etched surface implants and new hydrophilic surface implants in the posterior maxilla using a 3-month early-loading protocol: a randomized controlled trial. J Korean Assoc Oral Maxillofac Surg 2021

\section{Results}

The average age of all participants was 58.6 years, and ages ranged from 35 to 82 years. Among them, 13 patients (14 SA implants) in Group A and 14 patients (17 NH implants) in Group B were analyzed. Group A consisted of patients with an average age of 62.2 years (range, $48-80$ years), and Group B consisted of patients with an average age of 58.1 years (range, 35-82 years). The average diameter and length of the implants used in Group A were $4.86 \mathrm{~mm}$ and $8.82 \mathrm{~mm}$, respectively. Group B implants had an average diameter of $4.88 \mathrm{~mm}$ and an average length of $8.76 \mathrm{~mm}$. In Group A, 13 implants were placed as non-submerged (one-stage), and one implant was placed with a submerged (two-stage) approach. In Group B, 12 implants were installed in one stage, and five implants were installed in two stages. At implant placement, auxiliary surgery was performed on 13 implants in Group A and 14 implants in Group B. Nine SLwBG and four GBR surgeries were performed in Group A. In Group B, five SLwBG, three SLwBG with GBR, two SLwoBG, and one GBR procedure were implemented.(Table 1)

Primary stability was $73.86 \pm 6.40$ and $71.24 \pm 5.32$ in Groups A and B, respectively, and there was no statistically

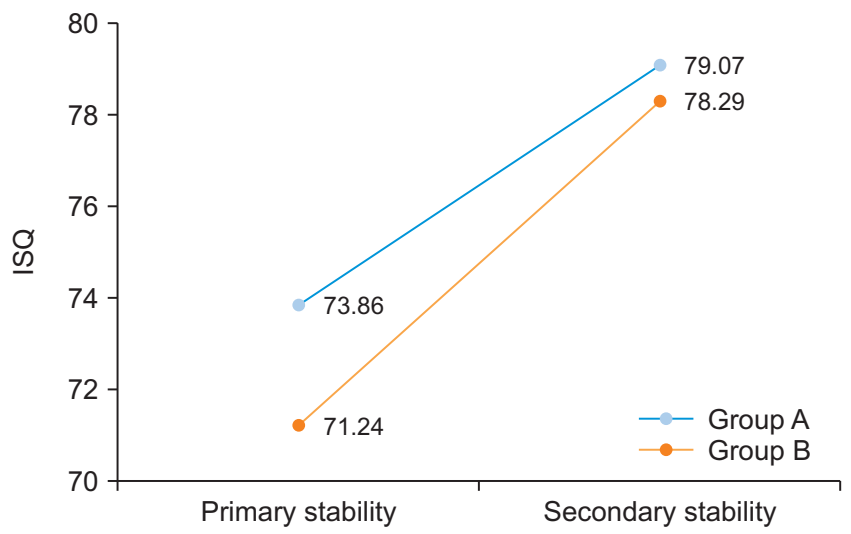

Fig. 3. Change of mean primary and secondary stability of the two groups of implants. (ISQ: implant stability quotient)

Hyeong Gi Kim et al: Comparison of sandblasted and acid-etched surface implants and new hydrophilic surface implants in the posterior maxilla using a 3-month early-loading protocol: a randomized controlled trial. J Korean Assoc Oral Maxillofac Surg 2021

significant difference between groups $(P=0.222$, Student's $t$-test). Secondary stability was $79.07 \pm 5.21$ in Group A and $78.29 \pm 4.74$ in Group B, the difference of which was not statistically significant ( $P=0.667$, Student's $t$-test). Intra-group difference of ISQ changes during the healing period exhibited a significant increase in both Groups A and B $(P<0.001$, both, paired $t$-test).(Table 2, Fig. 2) The mean ISQ increase during the healing period was $5.21 \pm 4.00$ in Group A and 7.06 \pm 4.58 in Group B. A steep increase in ISQ during the healing period was observed in Group B, but there was no significant intergroup difference ( $P=0.265$, Student's $t$-test).(Fig. 3$)$

The mean follow-up period from time of implant placement to most recent visit was $378.5 \pm 164.6$ days in Group A and $385.3 \pm 167.9$ days in Group B. The MBL during this period was $0.045 \pm 0.053 \mathrm{~mm}$ in Group A and $0.032 \pm 0.042 \mathrm{~mm}$ in Group B, and the difference was not significant $(P=0.457$, Student's $t$-test). MBL according to surgery type (nonsubmerged vs submerged) showed no significant difference between Groups A and B ( $P=0.143$ and 0.115 , respectively, Mann-Whitney test). There was no significant difference in MBL according to type of auxiliary surgery in Group A ( $P=0.565$, Kruskal-Wallis test). In Group B, there was no significant difference with respect to MBL in most cases with 
auxiliary surgery $(P>0.05$, post-hoc analyses using MannWhitney U tests following Kruskal-Wallis tests). However, there was a significant difference between cases where SLw$\mathrm{BG}$ and GBR were performed together and cases where auxiliary surgery was not performed ( $P=0.024$, post-hoc analysis using Mann-Whitney U test following Kruskal-Wallis test).

All implants in both Groups A and B were well-maintained until the most recent visit, with no signs of peri-implantitis, increased mobility, or patient discomfort. Every implant in both groups satisfied the success criteria. Accordingly, the aggregated success rate and survival rate were $100 \%$ for each group.

\section{Discussion}

Implant stability has been recognized as a requirement for long-term success and implant osseointegration ${ }^{9,10}$. Primary stability is the mechanical connection between implant surface and alveolar bone, while secondary stability is established as bone remodeling occurs ${ }^{11}$. Primary stability is a prerequisite for immediate loading and is an indicator of shortened treatment period ${ }^{2,12}$. In addition, secondary stability is an index that can determine if osseointegration has been obtained, with a low value representing implant failure ${ }^{13}$. Reports have indicated that the implant surface treatment method is a major factor that can affect the mechanical stability of implants ${ }^{14,15}$.

Among the various implant surface treatment methods, the HA coating method reportedly exhibits excellent biocompatibility as a constituent of bone tissue, resulting in fair ossointegration ${ }^{16,17}$. However, the HA can peel off the implant surface, and issues such as inhibition of osseointegration and peri-implantitis have been reported ${ }^{18,19}$. These issues have been overcome by reducing the size of the coated HA particles. Consequently, nano HA-coated implants with higher surface area and reactivity have shown superior clinical results compared to conventional HA-coated implants ${ }^{20}$. Ultrathin HA-coated implants also exhibited more favorable bone-implant contact and less MBL compared to conventional HA-coated implants in peri-implantitis-induced animal models ${ }^{21}$. The NH implants also used in this experiment have hydrophilicity via coating of a partial layer of bioabsorbable nano HA of $10 \mathrm{~nm}$ or less on the surface of SLA implants and were developed to take advantage of both SLA and nano HA surfaces $^{22}$.

In this study, although there was no statistical difference in primary stability between the two groups, the arithmetic mean ISQ was slightly lower in NH implants compared to SA implants. After the 2.5-month healing period, there was no significant difference in secondary stability between the groups. Each group exhibited a statistically significant increase in stability during the period, and the mean increase in ISQ was higher in the NH implant group than in the SA implant group, even though there was no statistical difference. This might be interpreted as rapid osseointegration in the $\mathrm{NH}$ implants, which initially had poorer bone quality at the recipient site, resulting in ISQ recovery during the healing period. This phenomenon can be explained by the hydrophilicity of NH implants. Hydrophilic surfaces exhibit a higher affinity for proteins than do hydrophobic surfaces. The structure and function of proteins are well-maintained on hydrophilic surfaces, while protein denaturation can be induced in implants with hydrophobic surfaces ${ }^{23,24}$. It has been suggested that high hydrophilicity promotes maturation and differentiation of osteoblasts, which can contribute to osseointegration ${ }^{25,26}$. Accordingly, research has suggested that use of implants with a hydrophilic surface can accelerate secondary stability improvement ${ }^{26}$. As shown in this study, the steep increase in ISQ in NH implants during the healing period appears to be due to osseointegration acceleration due to surface hydrophilicity.

Several non-invasive methods have been suggested for evaluating osseointegration of dental implants. The tapping test and radiographic test can be performed easily but can be inaccurate $^{27,28}$. A method of analyzing the mechanical stability of implants by measuring resonance frequency created by connecting a transducer to the implants has been widely used to overcome this limitation. The measured value obtained by RFA is presented as an ISQ from 1 to 100 , which can be used as an index of osseointegration with a higher value representing greater stability of the implant ${ }^{29,30}$.

This study assessed cases with residual alveolar bone height of $4 \mathrm{~mm}$ or more and ISQ primary stability of 65 or greater. The recipient site capacity for securing initial stability of the installed implants should be established to allow crestal approached sinus lifting and simultaneous implant placement. In this study, an ISQ of 65, which is considered appropriate initial stability, was set as a reference value based on previous studies that reported mechanical stability or prognosis after implant placement using RFA. Nedir et al. ${ }^{13}$ suggested that implants with an ISQ of 47 or higher be regarded as stable, and that an ISQ of 49 or higher immediately after implant placement resulted in osseointegration in all implants after 3 months of healing. Balleri et al. ${ }^{30}$ reported that successful 
osseointegration can be predicted by an ISQ of 57 to 82 immediately after implant placement and stated that an ISQ of 50 or less was associated with poor prognosis. An ISQ above 65 typically indicates optimal osseointegration, and an ISQ below 50 indicates failure or increased risk of failure of the implant $^{31,32}$. The average ISQ value of all implants analyzed in this study was 72.42 immediately after placement and 78.65 after 2.5 months; based on previous study results, these values represent good initial stability, which confirmed that sufficient osseointegration had occurred.

Analysis of the impact of type of auxiliary surgery combined with implant placement on MBL indicated that the association was not significant for SA implants. However, greater MBL occurred in NH implants when SLwBG and GBR were performed simultaneously with implant placement compared to cases in which only implant placement was performed. Although the MBL was very low, with an average of $0.090 \mathrm{~mm}(0.060-0.110 \mathrm{~mm})$ per year, this result was in agreement with previous studies that suggested significant bone grafting as one of the factors that increased early implant failure ${ }^{33,34}$.

All 31 implants analyzed in this study functioned normally without any issues for an average of 382.3 days after installation, and all implants satisfied the success criteria on assessment. All implants maintained marginal bone level similar to the initial state regardless of group. Non-submerged surgery was performed in 25 of 31 implants $(80.6 \%)$, but there was no difference in MBL according to surgery type (nonsubmerged or submerged) in each group. These results indicate sufficient implant surface-bone contact to resist occlusal forces in not only SA implants, but also in $\mathrm{NH}$ implants. In addition, issues caused by HA layer peeling, which have been reported with conventional HA-coated implants, were not reported or observed in the partial nano $\mathrm{HA}$ layer of the $\mathrm{NH}$ implants.

The results of this study are in agreement with one-year follow-up studies on implants placed in the maxillary posterior region using an early loading protocol. Kim et al. ${ }^{35}$ reported a $97.0 \%$ one-year implant success rate in the maxillary posterior area after a 3-month loading period. Kim et al. ${ }^{36}$ also indicated a one-year success rate of $97.56 \%$ by applying a loading protocol between 6 and 12 weeks to an implant placed in the posterior edentulous part of the maxilla. Todorovic et al. ${ }^{37}$ reported a one-year success rate of $100 \%$ after 3 weeks of early loading on implants placed in the maxillary posterior region.
Taken together, these findings suggest that primary stability of an ISQ of 65 or higher in SA implants and NH implants placed in the edentulous posterior maxilla will produce successful osseointegration and favorable clinical outcomes with the 3-month early loading protocol.

There were some limitations to this study. First, the numbers of patients and implants included in each group were relatively small. This is because it was difficult to recruit a large number of patients to fit the study design due to the nature of the prospective randomized controlled clinical trial. Second, when bone grafting and/or GBR were performed, various types of bone substitutes were used and were not controlled. Third, cases involving various auxiliary surgeries, not just implant placement, were included, which might serve as additional variables in analysis of implant treatment results.

\section{Conclusion}

Two surface-treated implants, SLA surface and dual surface with enhanced hydrophilicity, placed on the posterior maxilla with a height of $4 \mathrm{~mm}$ or more of residual alveolar bone were treated successfully for an average of one year. The success was noted for cases with primary stability of 65 of ISQ or higher with a 3-month early loading protocol. Both surfacetreated implants exhibited very good osseointegration, and there was no difference between the two. Although there was no difference in mean stability over time between the groups, a catch-up tendency was observed in the new hydrophilic surface $(\mathrm{NH})$ implants as osseointegration accelerated during the healing period.

\section{ORCID}

Hyeong Gi Kim, https://orcid.org/0000-0003-4730-0396

Pil-Young Yun, https://orcid.org/0000-0001-6097-1229

Young-Kyun Kim, https://orcid.org/0000-0002-7268-3870

Il-hyung Kim, https://orcid.org/0000-0003-1386-6391

\section{Authors' Contributions}

P.Y.Y. and Y.K.K. designed the study. H.G.K. collected and inputted study data. I.K. and P.Y.Y. performed all analyses and contributed to the data analysis strategy. H.G.K. and I.K. wrote the manuscript, while Y.K.K. and I.K. contributed to the interpretation of results and write-up of the manuscript. I.K. and Y.K.K. substantially revised the manuscript. 


\section{Acknowledgements}

The authors acknowledge the assistance provided by NaHee Chang in the Biomedical Research Institute of Seoul National University Bundang Hospital.

\section{Ethics Approval and Consent to Participate}

This study was conducted under approval of the Institutional Review Board (IRB No. B-1802/451-004) of Seoul National University Bundang Hospital (Seongnam, Korea), and the written informed consent was obtained from all patients.

\section{Conflict of Interest}

No potential conflict of interest relevant to this article was reported.

\section{References}

1. Brånemark PI, Hansson BO, Adell R, Breine U, Lindström J, Hallén $\mathrm{O}$, et al. Osseointegrated implants in the treatment of the edentulous jaw. Experience from a 10-year period. Scand J Plast Reconstr Surg Suppl 1977;16:1-132.

2. Zhang S, Wang S, Song Y. Immediate loading for implant restoration compared with early or conventional loading: a meta-analysis. J Craniomaxillofac Surg 2017;45:793-803. https://doi.org/10.1016/ j.jcms.2016.05.002

3. Huynh-Ba G, Oates TW, Williams MAH. Immediate loading vs. early/conventional loading of immediately placed implants in partially edentulous patients from the patients' perspective: a systematic review. Clin Oral Implants Res 2018;29 Suppl 16:255-69. https://doi.org/10.1111/clr.13278

4. Sommer M, Zimmermann J, Grize L, Stübinger S. Marginal bone loss one year after implantation: a systematic review of different loading protocols. Int J Oral Maxillofac Surg 2020;49:121-34. https://doi.org/10.1016/j.ijom.2019.03.965

5. Wennerberg A, Albrektsson T. On implant surfaces: a review of current knowledge and opinions. Int J Oral Maxillofac Implants 2010;25:63-74

6. Albrektsson T, Wennerberg A. On osseointegration in relation to implant surfaces. Clin Implant Dent Relat Res 2019;21 Suppl 1:4-7. https://doi.org/10.1111/cid.12742

7. Sargolzaie N, Samizade S, Arab H, Ghanbari H, Khodadadifard L, Khajavi A. The evaluation of implant stability measured by resonance frequency analysis in different bone types. J Korean Assoc Oral Maxillofac Surg 2019;45:29-33. https://doi.org/10.5125/ jkaoms.2019.45.1.29

8. Zarb GA, Albrektsson T. Consensus report: towards optimized treatment outcomes for dental implants. J Prosthet Dent 1998;80:641. https://doi.org/10.1016/s0022-3913(98)70048-4

9. Albrektsson T. Direct bone anchorage of dental implants. J Prosthet Dent 1983;50:255-61. https://doi.org/10.1016/00223913(83)90027-6

10. Rabel A, Köhler SG, Schmidt-Westhausen AM. Clinical study on the primary stability of two dental implant systems with resonance frequency analysis. Clin Oral Investig 2007;11:257-65. https://doi. org/10.1007/s00784-007-0115-2

11. Raghavendra S, Wood MC, Taylor TD. Early wound healing around endosseous implants: a review of the literature. Int J Oral Maxillofac Implants 2005;20:425-31.

12. Szmukler-Moncler S, Piattelli A, Favero GA, Dubruille JH. Considerations preliminary to the application of early and immediate loading protocols in dental implantology. Clin Oral Implants Res 2000;11:12-25. https://doi.org/10.1034/j.16000501.2000.011001012.x

13. Nedir R, Bischof M, Szmukler-Moncler S, Bernard JP, Samson J. Predicting osseointegration by means of implant primary stability. Clin Oral Implants Res 2004;15:520-8. https://doi.org/10.1111/ j.1600-0501.2004.01059.x

14. Schwartz Z, Nasazky E, Boyan BD. Surface microtopography regulates osteointegration: the role of implant surface microtopography in osteointegration. Alpha Omegan 2005;98:9-19.

15. Gottlow J, Barkarmo S, Sennerby L. An experimental comparison of two different clinically used implant designs and surfaces. Clin Implant Dent Relat Res 2012;14 Suppl 1:e204-12. https://doi. org/10.1111/j.1708-8208.2012.00439.x

16. Block MS, Kent JN, Kay JF. Evaluation of hydroxylapatitecoated titanium dental implants in dogs. J Oral Maxillofac Surg 1987;45:601-7. https://doi.org/10.1016/0278-2391(87)90270-9

17. Yang GL, He FM, Hu JA, Wang XX, Zhao SF. Biomechanical comparison of biomimetically and electrochemically deposited hydroxyapatite-coated porous titanium implants. J Oral Maxillofac Surg 2010;68:420-7. https://doi.org/10.1016/j.joms.2009.09.014

18. Lee JJ, Rouhfar L, Beirne OR. Survival of hydroxyapatitecoated implants: a meta-analytic review. J Oral Maxillofac Surg 2000;58:1372-9; discussion 1379-80. https://doi.org/10.1053/ joms.2000.18269

19. Yang Y, Kim KH, Ong JL. A review on calcium phosphate coatings produced using a sputtering process--an alternative to plasma spraying. Biomaterials 2005;26:327-37. https://doi.org/10.1016/ j.biomaterials.2004.02.029

20. Yazdani J, Ahmadian E, Sharifi S, Shahi S, Maleki Dizaj S. A short view on nanohydroxyapatite as coating of dental implants. Biomed Pharmacother 2018;105:553-7. https://doi.org/10.1016/ j.biopha.2018.06.013

21. Madi M, Zakaria O, Ichinose S, Kasugai S. Effect of induced periimplantitis on dental implants with and without ultrathin hydroxyapatite coating. Implant Dent 2016;25:39-46. https://doi. org/10.1097/ID.0000000000000331

22. Tallarico M, Baldini N, Martinolli M, Xhanari E, Kim YJ, Cervino $\mathrm{G}$, et al. Do the new hydrophilic surface have any influence on early success rate and implant stability during osseointegration period? Four-month preliminary results from a split-mouth, randomized controlled trial. Eur J Dent 2019;13:95-101. https://doi. org $/ 10.1055 / \mathrm{s}-0039-1688737$

23. Brett PM, Harle J, Salih V, Mihoc R, Olsen I, Jones FH, et al. Roughness response genes in osteoblasts. Bone 2004;35:124-33. https://doi.org/10.1016/j.bone.2004.03.009

24. Terheyden H, Lang NP, Bierbaum S, Stadlinger B. Osseointegration--communication of cells. Clin Oral Implants Res 2012;23:1127-35. https://doi.org/10.1111/j.1600-0501.2011.02327. $\mathrm{x}$

25. Zhao G, Schwartz Z, Wieland M, Rupp F, Geis-Gerstorfer J, Cochran DL, et al. High surface energy enhances cell response to titanium substrate microstructure. J Biomed Mater Res A 2005;74:4958. https://doi.org/10.1002/jbm.a.30320

26. Smeets R, Stadlinger B, Schwarz F, Beck-Broichsitter B, Jung O, Precht $\mathrm{C}$, et al. Impact of dental implant surface modifications on osseointegration. Biomed Res Int 2016;2016:6285620. https://doi. org/10.1155/2016/6285620

27. Adell R, Lekholm U, Rockler B, Brånemark PI. A 15-year study of osseointegrated implants in the treatment of the edentulous jaw. 
Int J Oral Surg 1981;10:387-416. https://doi.org/10.1016/s03009785(81)80077-4

28. Sundén S, Gröndahl K, Gröndahl HG. Accuracy and precision in the radiographic diagnosis of clinical instability in Brånemark dental implants. Clin Oral Implants Res 1995;6:220-6. https://doi. org/10.1034/j.1600-0501.1995.060404.x

29. Meredith N, Alleyne D, Cawley P. Quantitative determination of the stability of the implant-tissue interface using resonance frequency analysis. Clin Oral Implants Res 1996;7:261-7. https://doi. org/10.1034/j.1600-0501.1996.070308.x

30. Balleri P, Cozzolino A, Ghelli L, Momicchioli G, Varriale A. Stability measurements of osseointegrated implants using Osstell in partially edentulous jaws after 1 year of loading: a pilot study. Clin Implant Dent Relat Res 2002;4:128-32. https://doi.org/10.1111/ j.1708-8208.2002.tb00162.x

31. Atsumi M, Park SH, Wang HL. Methods used to assess implant stability: current status. Int J Oral Maxillofac Implants 2007;22:74354.

32. Herekar M, Sethi M, Ahmad T, Fernandes AS, Patil V, Kulkarni H. A correlation between bone (B), insertion torque (IT), and implant stability (S): BITS score. J Prosthet Dent 2014;112:805-10. https:// doi.org/10.1016/j.prosdent.2014.02.011

33. Baqain ZH, Moqbel WY, Sawair FA. Early dental implant failure: risk factors. Br J Oral Maxillofac Surg 2012;50:239-43. https://doi. org/10.1016/j.bjoms.2011.04.074

34. Chrcanovic BR, Kisch J, Albrektsson T, Wennerberg A. Factors influencing early dental implant failures. J Dent Res 2016;95:9951002. https://doi.org/10.1177/0022034516646098
35. Kim SB, Yun PY, Kim SY, Yi YJ, Kim JY, Kim YK. Prospective randomized clinical trial of hydrophilic tapered implant placement at maxillary posterior area: 6 weeks and 12 weeks loading. J Adv Prosthodont 2016;8:396-403. https://doi.org/10.4047/ jap.2016.8.5.396

36. Kim YK, Kim JH, Yi YJ, Kwon MJ, Yun PY. Prospective comparative study of tapered implants with SLA surfaces in the maxillary posterior area according to 3- and 6-month loading time. Int J Periodontics Restorative Dent 2015;35:271-6. https://doi.org/10.11607/ prd.1789

37. Todorovic VS, Vasovic M, Beetge MM, van Zyl AW, Kokovic V. Stability development of immediately loaded hybrid self-tapping implants inserted in the posterior maxilla: 1-year results of a randomized controlled trial. J Oral Implantol 2017;43:33-8. https:// doi.org/10.1563/aaid-joi-D-16-00143

How to cite this article: Kim HG, Yun PY, Kim YK, Kim I. Comparison of sandblasted and acid-etched surface implants and new hydrophilic surface implants in the posterior maxilla using a 3-month early-loading protocol: a randomized controlled trial. J Korean Assoc Oral Maxillofac Surg 2021;47:175-182. https://doi. org/10.5125/jkaoms.2021.47.3.175 